\title{
Karakteristik Fisikokimia Pati Ubi Banggai (Dioscorea alata)
}

\author{
Physicochemical Characterization of Banggai Yam (Dioscorea alata) Starches \\ Mimah Mutmainah ${ }^{1}$, Feri Kusnandar ${ }^{1,2}$, Tjahja Muhandri ${ }^{1,2}$ \\ ${ }^{1}$ Departemen Ilmu dan Teknologi Pangan, Fakultas Teknologi Pertanian, Institut Pertanian Bogor, \\ Kampus IPB Dramaga, Bogor, 16680, Indonesia \\ ${ }^{2}$ Southeast Asian Food and Agricultural Science and Technology Center, Institut Pertanian Bogor, \\ Kampus IPB Dramaga, Bogor, 16680, Indonesia \\ *Penulis korespondensi: Feri Kusnandar, Email: fkusnandar@apps.ipb.ac.id; mimah.mutmainah@yahoo.co.id
}

Tanggal submisi: 13 Desember 2019; Tanggal revisi: 2 April 2020, 17 April 2020; Tanggal penerimaan: 3 Juli 2020

\begin{abstract}
ABSTRAK
Ubi Banggai merupakan ubi khas dari Kepulauan Banggai, dengan jumlah varietas yang banyak. Ubi Banggai merupakan sumber karbohidrat yang salah satu komponen penyusunnya adalah pati. Karakteristik fisikokimia pati dari ubi Banggai belum diketahui, sehingga penelitian ini bertujuan untuk mengevaluasi karakteristik pati dari tiga varietas ubi Banggai (Baku Pusus, Baku Tuu Oloyo, dan Baku Boan). Pati ubi Banggai diekstraksi dan dianalisis sifat fisikokimianya yang meliputi kadar pati, amilosa, amilopektin, morfologi granula, warna, profil pasting, kemampuan mengembang, kelarutan, kekuatan gel, dan sineresis. Rendemen setiap varietas relatif rendah, yaitu Baku Pusus (8,66\%), Baku Tuu oloyo (5,09\%) dan Baku Boan (4,56\%). Ketiga varietas mengandung kadar pati $88,00-88,89 \%$, yang disusun oleh $60,29-62,88 \%$ amilosa dan amilopektin $25,12-28,65 \%$. Granula pati ubi Banggai berbentuk ellipsoid, polyhedral, dan triangular dengan ukuran panjang 17,94-23,59 $\mu \mathrm{m}$ dan lebar 13,97$16,72 \mu \mathrm{m}$. Hasil analisis warna pati kering ubi Banggai menunjukkan ubi Baku Pusus dan Baku Tu Oloyo memiliki nilai whiteness index (WI) yang tinggi dan browning index (BI) yang rendah, sedangkan pati ubi Baku Boan memiliki nilai WI yang paling rendah dan nilai BI paling tinggi. Hasil analisis RVA menunjukkan pati ubi Banggai memiliki suhu pasting yang tinggi $\left(80,10-80,35^{\circ} \mathrm{C}\right)$. Pada fase pemanasan, pasta ubi Banggai memiliki viskositas puncak yang tinggi dan mengalami viskositas breakdown. Pada fase pendinginan, pasta ubi Banggai memiliki viskositas setback dan viskositas akhir yang tinggi. Pati Baku Pusus memiliki kelarutan yang tinggi, kemampuan mengembang yang terbatas, kekuatan gel yang tinggi, namun mengalami sineresis.
\end{abstract}

Kata kunci: Amilosa; ubi banggai; profil pasting; granula pati

\begin{abstract}
Banggai is a typical yam native to Banggai Island with a large number of varieties. It functions as a source of carbohydrate, especially starch. The physicochemical characteristics of Banggai yam starch are unknown, therefore, this study aims to investigate the starch characteristics of three Banggai yam varieties namely (Baku Pusus, Baku Tuu Oloyo, and Baku Boan). The starch was extracted and analyzed for the physicochemical properties including, amylose, and amylopectin contents, granule morphology, color, pasting properties, solubility, swelling power, gel strength, and syneresis. The results showed that the wet starch extraction of Banggai yam was relatively low, i.e., Baku Pusus (8.66\%), Baku Tuu oloyo (5.09\%) and Baku Boan (4.56\%). Furthermore, the three varieties contained starch ranging from $88.00-88.89 \%$ which composed of amylose $(60.29-62.88 \%)$ and
\end{abstract}


amylopectin (25.12-28.65\%). The starch granules showed ellipsoid, polyhedral, and triangular forms with lengths ranging from 17.94-23.59 $\mu \mathrm{m}$ and widths of 13.97-16.72 $\mu \mathrm{m}$. The RVA profiles showed that the starches had high initial pasting temperatures $\left(80.10-80.35^{\circ} \mathrm{C}\right)$, high peak and end viscosity, experienced viscosity breakdown during the heating phase, while the cold paste had a high setback viscosity. Based on the results, Baku Pusus had the highest solubility, limited swelling power with a high gel strength, and experienced syneresis.

Keywords: Amylose banggai yam; pasting properties; starch granules

\section{PENDAHULUAN}

Tanaman ubi Banggai (Dioscorea alata) merupakan kelompok tanaman umbi-umbian yang banyak dibudidayakan di Banggai Kepulauan (Bangkep) Sulawesi Tengah. Di wilayah tersebut, ubi Banggai merupakan salah satu makanan pokok masyarakat asli Bangkep. Boy dan Soeharsomo (2013) mengidentifikasi 44 varietas ubi Banggai dengan nama lokal Baku yang tumbuh di Bangkep dengan produksi mencapai 4069 ton pada tahun 2012, dan sebanyak 35 varietas di antaranya terdaftar di Kementerian Pertanian.

Setiap varietas ubi Banggai mempunyai perbedaan tekstur kulit, warna daging dan bentuk umbinya. Yusuf dkk. (2015) menyebutkan tiga varietas ubi Banggai yang banyak dikonsumsi dan memiliki rasa yang enak, yaitu Baku Tuu, Baku Pusus, dan Baku Boan. Ketiga varietas tersebut dapat diproduksi dengan rata-rata 10-30 ton/ha.

Rahardjo dkk. (2016) melaporkan kadar pati tepung ubi Banggai berkisar antara 70,96-84,71\% yang berpotensi sebagai sumber pati baru. Secara umum, pasta pati kelompok $D$. alata memiliki viskositas yang tinggi, karakteristik gel yang stabil, tahan pemanasan dan penyimpanan sehingga berpotensi untuk diaplikasikan pada industri pangan sebagai pengental atau pembentuk gel (Nadia dkk., 2014). Oke dkk. (2013) melaporkan bahwa pati $D$. alata memiliki kadar amilosa yang lebih tinggi dibandingkan jenis umbiumbian lainnya, yaitu antara $27,47-41,90 \%$. Kandungan amilosa yang tinggi dapat memperbaiki tekstur produk pangan menjadi lebih kokoh dan cocok digunakan sebagai bahan pembentuk gel atau film.

Berbeda dari kelompok ubi lainnya, ubi Banggai banyak mengandung lendir. Komponen utama penyusun lendir pada kelompok tanaman Dioscorea merupakan glukomanan yang memiliki sifat hidrokoloid yang kuat. Komponen tersebut bisa dimanfaatkan sebagai bahan penstabil untuk memperbaiki tekstur produk pangan (Yeh dkk., 2009). Lendir yang terdapat pada ubi Banggai mempersulit dalam proses pengolahannya, sehingga lendir tersebut harus dihilangkan terlebih dahulu. Perendaman dengan larutan $\mathrm{NaCl} 15 \%$ selama 60 menit dapat menghilangkan lendir pada irisan Dioscorea (Nadia dkk., 2014).
Penggunaan pati alami dalam proses pengolahan pangan perlu mempertimbangkan karakteristik fisikokimianya (Jayakody dkk., 2007). Karakteristik fisikokimia seperti kadar amilosa, profil pasting, kelarutan, daya mengembang, kekuatan gel dan derajat sineresis dari pati ubi Banggai masih belum tersedia sehingga potensi aplikasinya dalam pengolahan pangan belum banyak diketahui. Oleh sebab itu, penelitian ini bertujuan untuk mengevaluasi sifat fisikokimia pati dari tiga varietas ubi Banggai (Baku Pusus, Baku Tuu Oloyo dan Baku Boan) dan mengidentifikasi potensi aplikasinya dalam pengolahan pangan.

\section{METODE PENELITIAN}

\section{Bahan dan Alat}

Ubi Banggai (Baku Pusus, Baku Tuu Oloyo dan Baku Boan) diperoleh dari Desa Gansal, Kecamatan Tinangkung Selatan, Kabupaten Banggai Kepulauan. Ubi Banggai yang digunakan adalah yang memiliki umur panen delapan bulan pada musim tanam bulan September 2018 dan diperoleh dari lokasi tanam dan petani yang sama. Peralatan penelitian yang digunakan antara lain mesin pemarut kelapa (Bogor, Indonesia), cabinet dryer (Bogor, Indonesia), blender kering (Turbo, Jepang), ayakan 100 mesh (Bogor, Indonesia), spektrofotometer UV-Vis (Genesys 150, USA), Rapid Visco Analyzer (RVA-TecMaster, Australia), mikroskop polarisasi cahaya (Olympus BH-2, Jepang), Chromamometer CR-400/410 (Konica Minolia, Jepang) dan Texture Analyzer Stable MicroSystem (TA-XT2i, USA).

\section{Ekstraksi Pati}

Proses ekstraksi pati ubi Banggai mengacu pada metode Nadia dkk. (2014) dengan modifikasi. Ubi dikupas, dibersihkan, dipotong-potong dan direndam dalam larutan $\mathrm{NaCl} 15 \%$ selama 60 menit. Perendaman bertujuan untuk menghilangkan lendir. Ubi yang telah direndam kemudian dicuci dengan air mengalir sampai bersih dan kembali ditampung dalam wadah berisi air bersih. Ubi kemudian diparut dengan menggunakan 
mesin pemarut kelapa. Slurry yang dihasilkan ditimbang, lalu ditambah larutan natrium metabisulfit $0,1 \%$ dengan perbandingan $1: 4$ yang bertujuan untuk mencegah reaksi pencoklatan. Slurry disaring dengan menggunakan kain saring, dan diperas. Suspensi yang diperoleh ditampung dalam wadah dan diendapkan selama 6 jam sampai terbentuk endapan pati berwarna putih. Filtrat dibuang, dan endapan dicuci dengan rasio antara endapan pati dan air adalah 1:2, lalu diendapkan kembali selama 13 jam. Filtrat dibuang dan endapan dicuci kembali dengan rasio yang sama, kemudian diendapkan kembali selama 6 jam. Setelah itu filtrat dibuang dan endapan pati dipindahkan ke dalam loyang besar, dan dikeringkan dalam cabinet $\operatorname{dryer}\left(50^{\circ} \mathrm{C}, 3\right.$ jam). Pati kering dihaluskan dengan menggunakan blender kering, lalu diayak dengan ayakan 100 mesh. Pati dikemas menggunakan plastik polietilen dan disimpan dalam freezer $\left(-16^{\circ} \mathrm{C}\right)$ hingga analisis dilakukan.

Pati hasil ekstraksi selanjutnya dianalisis sifat fisikokimianya. Analisis kimia mencakup kadar air (AOAC, 2012), kadar abu (AOAC, 2012), kadar pati dan kadar amilosa, sedangkan analisis fisik mencakup morfologi granula pati, warna pati, profil pasting, kemampuan mengembang (swelling power), kelarutan (solubility), kekuatan gel dan derajat sineresis.

\section{Analisis Kadar Pati ((Miller, 1959) dengan Modifikasi)}

Analisis kadar pati ditentukan secara spektrofotometri menggunakan 3,5 dinitrosalicylicacid (DNS). Sampel dicuci/dimurnikan untuk menghilangkan pengotor dan gula sederhana dengan cara sebanyak $100 \mathrm{mg}$ sampel pati dimasukkan ke dalam tabung reaksi berulir, lalu ditambahkan $5 \mathrm{~mL}$ dietileter, divortex dan disentrifugasi selama 5 menit dengan menggunakan hand-sentrifuge. Supernatan dipisahkan dan endapannya dikeringkan dengan menggunakan gas nitrogen. Endapan yang telah kering dicuci kembali dengan etanol $80 \%$ dan dikeringkan di atas penangas air pada suhu $60-80{ }^{\circ} \mathrm{C}$. Sampel kemudian dihidrolisis dengan menambahkan $3 \mathrm{~mL}$ larutan $\mathrm{HCl} 10 \%$, di-vortex dan dipanaskan dalam penangas air pada suhu 100 ${ }^{\circ} \mathrm{C}$ selama 2,5 jam dan setiap 30 menit dihomogenkan menggunakan vortex. Larutan sampel yang telah dihidrolisis lalu didinginkan dan dipindahkan ke dalam Erlenmeyer secara kuantitatif, dan $\mathrm{pH}$ larutan sampel dinetralkan $(7,0 \pm 0,1)$. Larutan sampel yang telah netral disaring ke dalam labu ukur dan ditambahkan aquades sampai volume tepat $100 \mathrm{~mL}$.

Sebanyak 0,5 mL larutan sampel dimasukkan ke dalam tabung reaksi berulir, lalu ditambahkan $1,5 \mathrm{~mL}$ aquades dan $3 \mathrm{~mL}$ larutan DNS. Campuran dihomogenkan dengan vortex dan diinkubasi selama 10 menit dalam penangas air mendidih. Sampel didinginkan pada suhu ruang dan absorbansinya diukur dengan UVVis spektrofotometer pada panjang gelombang 540 $\mathrm{nm}$ terhadap blanko. Langkah tersebut diulangi untuk membuat kurva standar glukosa $(40,60,80,100,120$, dan $140 \mathrm{ppm}$ ) dari larutan stok dengan konstentrasi $1000 \mathrm{ppm}$.

\section{Analisis Kadar Amilosa dan Amilopektin ((AACC, 1999) dengan Modifikasi)}

Kadar amilosa pati ubi Banggai ditentukan secara spektrofotometri sedangkan kadar amilopektin ditentukan sebagai selisih antara kadar pati dengan amilosa. Sebanyak $100 \mathrm{mg}$ pati dimasukkan ke dalam tabung reaksi berulir, lalu ditambahkan $1 \mathrm{~mL}$ etanol 95\% dan 9 $\mathrm{mL} \mathrm{NaOH}$, lalu dihomogenkan dengan vortex. Campuran didiamkan selama 10 menit pada suhu ruang, dipanaskan dengan penangas air mendidih selama 30 menit (setiap 10 menit dihomogenkan dengan vortex). Sampel didinginkan dan dipindahkan ke dalam labu takar 100 $\mathrm{mL}$ secara kuantitatif, lalu ditambahkan aquades sampai tepat $100 \mathrm{~mL}$. Sebanyak 0,5 mL larutan sampel dipipet, dimasukkan ke dalam tabung reaksi berulir ditambahkan $0,5 \mathrm{~mL}$ larutan $\mathrm{CH}_{3} \mathrm{COOH} 1 \mathrm{~N}$ dan 0,25 mL larutan iod 0,01 $\mathrm{N}$ kemudian diencerkan hingga $10 \mathrm{~mL}$ dengan menambahkan aquades. Langkah yang sama dilakukan untuk larutan standar pada konsentrasi 0,008; 0,016; 0,024; 0,032; dan 0,040 mg/mL dari larutan stok dengan konsentrasi $0,4 \mathrm{mg} / \mathrm{mL}$. Masing-masing larutan diukur absorbansinya menggunakan UV-Vis spektrofotometer pada panjang gelombang $620 \mathrm{~nm}$ terhadap blanko.

\section{Analisis Warna}

Warna pati dianalisis dengan menggunakan Chromamometer CR-400/410. Instrumen dikalibrasi terlebih dahulu menggunakan plat standar putih. Sampel diletakkan secara merata ke dalam cawan (GranularMaterials Attachment CR-A50) kemudian kepala optik ditempelkan pada sampel lalu diukur. Parameter yang diukur adalah nilai $L$, $a$, dan $b$ dan hasil pengukuran merupakan rata-rata dari tiga ulangan. Selanjutnya, nilai $L, a$, dan $b$ dikonversi menjadi nilai whiteness index dan browning index dengan Persamaan 1, 2, dan 3 (Hirschler, 2012).

$$
\begin{aligned}
& W I=100-\sqrt{\left(100-L^{*}\right)^{2}+a^{* 2}+b^{* 2}} \\
& B I=\frac{100(x-0,31)}{0,17} \\
& x=\frac{\left(a^{*}+1,75 L\right)}{\left(5,645 L^{*}+a^{*}-0,012 b^{*}\right)}
\end{aligned}
$$




\section{Morfologi Pati ((Pérez dkk., 2013) dengan Modifikasi)}

Morfologi granula pati yang terdiri dari bentuk, ukuran, dan sifat birefringence dianalisis dengan mikroskop polarisasi cahaya dengan alat bantu mikrometer okuler dan mikrometer objektif. Analisis bentuk dan sifat birefringence dilakukan dengan pengamatan visual. Analisis ukuran granula pati diawali dengan proses kalibrasi untuk mengetahui jarak antar garis pada mikrometer okuler dengan menggunakan mikrometer objektif. Setelah itu membuat preparat berupa suspensi dari $1 \mathrm{~g}$ pati ditambah $20 \mathrm{~mL}$ aquades. Preparat diteteskan di atas gelas objek dan ditutup dengan gelas penutup, lalu diamati di bawah mikroskop polarisasi cahaya dengan pembesaran 400 kali. Ukuran granula pati ditentukan berdasarkan perhitungan skala okuler pada ukuran lebar dan panjang granula yang berhasil didokumentasikan oleh kamera dengan 10 titik pengamatan untuk setiap varietas.

\section{Kemampuan Mengembang dan Kelarutan (Parwiyanti dkk., 2015)}

Analisis kemampuan mengembang dan kelarutan dilakukan secara bersamaan. Sebanyak 200 mg pati kering dimasukkan ke dalam tabung sentrifus, ditambahkan $10 \mathrm{~mL}$ aquades dan dihomogenkan dengan vortex selama 30 detik. Sampel kemudian dipanaskan dalam penangas air $\left(95{ }^{\circ} \mathrm{C}, 30\right.$ menit), sambil dihomogenkan setiap 10 menit, lalu didinginkan pada air mengalir dan disentrifugasi (1008 g, 30 menit). Bagian supernatan dipindahkan ke dalam cawan yang sudah diketahui beratnya kemudian dikeringkan dalam oven $105^{\circ} \mathrm{C}$ selama semalam, dan ditimbang sampai beratnya konstan. Bagian endapan didiamkan selama 10 menit dan ditimbang. Kemampuan mengembang dinyatakan sebagai persen pati basah $(\mathrm{g}$ ) terhadap pati kering ( $\mathrm{g}$ ) yang dikurangi dengan supernatan kering (g), sedangkan kelarutan dinyatakan sebagai persen supernatan kering $(\mathrm{g})$ terhadap pati kering $(\mathrm{g})$.

\section{Kekuatan Gel ((Wang dkk., 2016) dengan Modifikasi)}

Sebanyak $5 \mathrm{~g}$ sampel ditimbang dalam gelas kimia $500 \mathrm{~mL}$, ditambah $100 \mathrm{~mL}$ aquades dan dipanaskan dalam penangas air $\left(90{ }^{\circ} \mathrm{C}, 30\right.$ menit), dan setiap 5 menit dihomogenkan dengan batang pengaduk. Pasta pati dimasukkan ke dalam pipa paralon plastik (tinggi $4 \mathrm{~cm}$, diameter $3 \mathrm{~cm}$ ) yang telah diketahui beratnya, didinginkan kemudian ditimbang beratnya. Selanjutnya botol ditutup dan disimpan dalam kulkas pada suhu
$5{ }^{\circ} \mathrm{C}$ selama semalam (17 jam). Gel dikeluarkan dan didiamkan hingga mencapai suhu ruang, dan kekuatan gel dianalisis menggunakan Texture Analyzer (TA$\mathrm{XT} 2 \mathrm{i})$. Pengukuran dilakukan dengan menggunakan probe silinder ukuran 0,5 R berdiameter $35 \mathrm{~mm}$ dengan kondisi yang digunakan yaitu pre test speed $1 \mathrm{~mm} / \mathrm{s}$, test speed $1 \mathrm{~mm} /$ detik, post test speed $5 \mathrm{~mm} / \mathrm{s}$, repture test distance $1 \mathrm{~mm}$, distance $10 \mathrm{~mm}$, force $205 \mathrm{gf}$, dan waktu 5 detik. Data yang diperoleh dari grafik yang terbentuk dinyatakan sebagai kekuatan gel (gf).

\section{Derajat Sineresis ((Wang dkk., 2016) dengan Modifikasi)}

Sampel dari hasil analisis kekuatan gel disimpan semalaman dalam kulkas, lalu dipindahkan ke dalam freezer $\left(-16^{\circ} \mathrm{C}, 24\right.$ jam $)$ sebagai siklus ke-1. Setelah itu di-thawing dalam penangas air $\left(25^{\circ} \mathrm{C}, 2\right.$ jam), air yang terpisah dari gel pati dipindahkan ke dalam Erlenmeyer yang telah diketahui beratnya, dengan cara meletakkan gel pada corong dan didiamkan selama 1 jam sampai semua air menetes. Air yang terkumpul lalu ditimbang. Dengan cara yang sama dilakukan untuk siklus ke-2 dan 3. Derajat sineresis dinyatakan sebagai persen air yang keluar $(\mathrm{g})$ terhadap berat gel $(\mathrm{g})$.

\section{Profil Pasting Pati ((Oke dkk., 2013) dengan Modifikasi)}

Profil pasting pati ubi Banggai dianalisis dengan menggunakan Rapid Visco Analyzer (RVA). Analisis dilakukan dengan cara menimbang pati ubi Banggai sebanyak $3 \mathrm{~g}$ kemudian diletakkan dalam wadah sampel (canister) dan dilarutkan dengan $25 \mathrm{~mL}$ aquades. Campuran kemudian dihomogenkan menggunakan paddle sampai tidak ada yang menggumpal setelah itu diletakkan pada alat RVA kemudian dihomogenkan kembali dengan cara diputar pada kecepatan $960 \mathrm{rpm}$ selama 12 detik. Selanjutnya dilakukan analisis pada fase pemanasan dengan kecepatan putaran diatur pada $160 \mathrm{rpm}$ dan suhu awal $47^{\circ} \mathrm{C}$ dinaikkan menjadi $50{ }^{\circ} \mathrm{C}$, lalu dipertahankan selama 1 menit. Selanjutnya suhu dinaikkan menjadi $95{ }^{\circ} \mathrm{C}$ dengan kecepatan 5 ${ }^{\circ} \mathrm{C} /$ menit dan dipertahankan selama 5 menit. Sampel kemudian didinginkan dengan menurunkan suhu mencapai $50{ }^{\circ} \mathrm{C}$ dengan kecepatan $5{ }^{\circ} \mathrm{C} /$ menit dan dipertahankan selama 1 menit. Pembacaan pada alat akan menghasilkan kurva yang menunjukkan profil perubahan viskositas pasta pati pada fase pemanasan dan fase pendinginan beberapa parameter yang diperoleh, yaitu suhu pasting, viskositas puncak, viskositas breakdown, viskositas setback, dan viskositas akhir. Viskositas dinyatakan dalam cP. 


\section{Analisis Data}

Data hasil analisis diolah secara statistik dengan analisis ragam pada tingkat kepercayaan $95 \%$ dengan menggunakan Program Minitab 16. Jika hasil analisis memberikan pengaruh berbeda nyata, maka analisis dilanjutkan dengan uji Tukey pada taraf kepercayaan $5 \%$. Data dinyatakan dalam bentuk nilai rata-rata \pm standar deviasi.

\section{HASIL DAN PEMBAHASAN}

\section{Rendemen dan Warna Pati Ubi Banggai}

Gambar 1 menunjukkan tiga jenis ubi Banggai yang digunakan dalam penelitian ini. Ubi Baku Pusus (1a) berbentuk lonjong kulit berwarna coklat dengan permukaan yang kasar, tebal, terdapat dua lapisan seperti kulit singkong, dan dagingnya berwarna putih. Baku Tuu Oloyo memiliki karakteristik yang mirip dengan Baku Pusus, namun kulitnya lebih halus dan tipis serta kulit bagian dalam sedikit kekuningan, serta tekstur daging lebih halus dan lebih mudah browning setelah dikupas (Gambar 1b). Baku Boan memiliki bentuk bulat, kulit berwarna coklat muda, warna daging putih keunguan dan memiliki aroma yang khas, yaitu seperti wangi nasi beras pandan (Gambar 1c).

Hasil ekstraksi pati menghasilkan rendemen yang rendah, yaitu Baku Pusus $(8,66 \%)$, Baku Tuu oloyo $(5,09 \%)$ dan ubi Baku Boan (4,56\%). Richana dan Sunarti (2004) melaporkan bahwa rendemen pati umbi Dioscorea alata paling rendah $(4,56 \%)$ jika dibandingkan umbi ganyong, suweg, dan gembili berturut-turut ialah $12,93 \%, 11,56 \%$, dan $21,44 \%$. Hal yang menyebabkan rendahnya rendemen pati yang dihasilkan adalah besarnya proporsi kulit terutama pada ubi yang memiliki permukaan tidak merata yang menyulitkan proses pengupasan, sehingga bagian daging banyak yang terbuang. Faktor lainnya adalah lendir yang banyak terkandung pada ubi Banggai yang menyulitkan proses ekstraksi pati. Perendaman $\mathrm{NaCl}$ $15 \%$ hanya membersihkan lendir yang keluar dari permukaan daging setelah pengupasan, namun lendir kembali keluar dalam jumlah lebih banyak setelah proses pemarutan. Lendir tersebut menutupi lubanglubang pada kain saring sehingga proses pengepresan kurang maksimal.

Warna pati ubi Banggai dari ketiga varietas berbeda. Pati ubi Banggai dari varietas Baku Pusus dan Baku Tuu Oloyo berwarna putih khas pati, sedangkan pati varietas baku Boan agak berwarna putih keruh. Hasil analisis whiteness index (WI) dan browning index (BI) menunjukkan ubi Baku Pusus dan Baku Tu Oloyo memiliki nilai WI yang tinggi dan BI yang rendah, sedangkan pati ubi Baku Boan memiliki nilai WI yang paling rendah dan nilai BI paling tinggi (Tabel 1). Ketiga pati memiliki nilai WI yang lebih rendah dibandingkan tapioka. Bila dibandingkan dengan standar warna SNI, nilai WI pati Baku Pusus dan Baku Tuu Oloyo memenuhi standar warna SNI, sedangkan pati Baku Boan tidak memenuhi standar.

Varietas ubi Baku Boan memiliki warna daging putih keunguan yang diduga mengandung senyawa fenolik yang mudah mengalami pencoklatan enzimatis yang disebabkan oksidasi oleh enzim fenoloksidase dan peroksidase. Senyawa fenolik yang terkandung dalam tanaman $D$. alata berupa dimer katekin dan prosianidin (Krishnan dkk., 2010). Warna pati ubi Baku

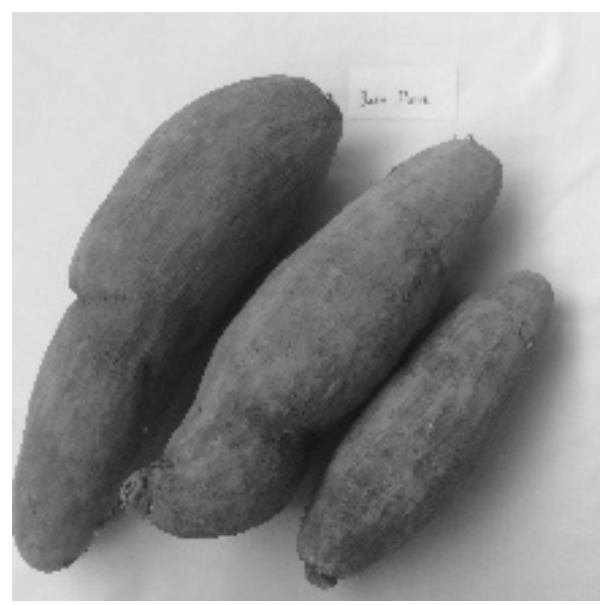

(a)

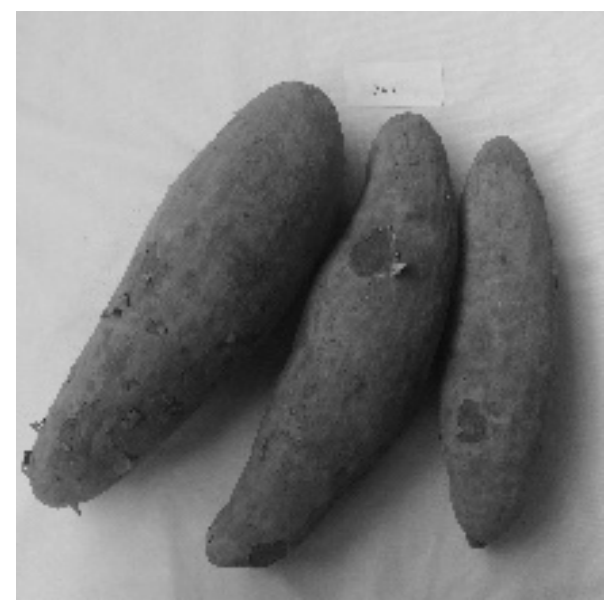

(b)

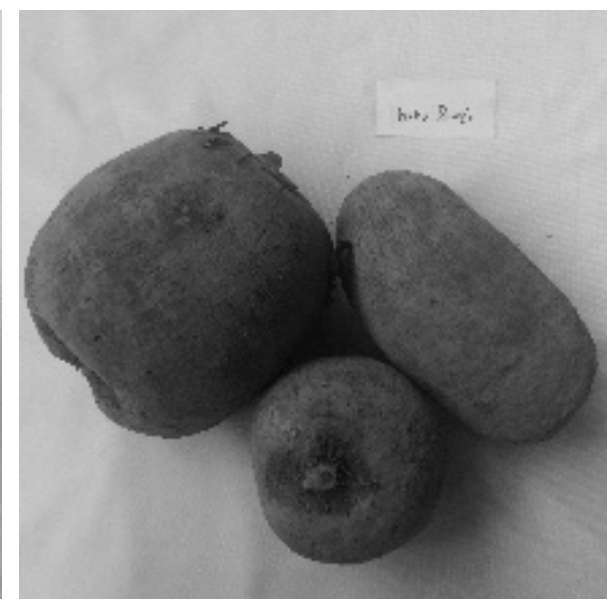

(c)

Gambar 1. Varietas Baku Pusus (a), Baku Tuu Oloyo (b), Baku Boan (c) 
Tabel 1. Karakteristik warna pati ubi Banggai

\begin{tabular}{lcc}
\hline Varietas & $\begin{array}{c}\text { Whiteness Index } \\
(\%)\end{array}$ & $\begin{array}{c}\text { Browning Index } \\
(\%)\end{array}$ \\
\hline Baku Pusus & $92,35 \pm 0,01^{\mathrm{b}}$ & $2,05 \pm 0,00^{\mathrm{c}}$ \\
Baku Tu oloyo & $91,47 \pm 0,00^{\mathrm{c}}$ & $1,94 \pm 0,01^{\mathrm{d}}$ \\
Baku Boan & $87,67 \pm 0,00^{\mathrm{d}}$ & $5,29 \pm 0,01^{\mathrm{a}}$ \\
Tapioka & $93,69 \pm 0,00^{\mathrm{a}}$ & $3,18 \pm 0,00^{\mathrm{b}}$ \\
\hline
\end{tabular}

Standar* min. 91

Keterangan: Huruf yang berbeda pada baris yang sama menunjukkan perbedaan yang signifikan $(p<0,05)$ *Standar mutu tapioka SNI: 3451.2011

Boan lebih gelap yang dibuktikan dengan nilai BI paling tinggi dibandingkan varietas lainnya. Perendaman menggunakan larutan natrium metabisulfit $0,1 \%$ sebagai anti browning agent dilakukan setelah proses pemarutan selesai, namun reaksi pencoklatan sudah berjalan saat slurry keluar dari pemarut, sehingga larutan tersebut tidak mampu mencegah reaksi pencoklatan secara maksimal.

\section{Morfologi Granula Pati}

Gambar 2 menunjukkan bentuk morfologi granula pati ubi Banggai. Ketiga pati memiliki bentuk dan ukuran granula pati yang utuh dan menunjukkan pola birefringenceyang menunjukkan proses ekstraksi pati ubi Banggai tidak merusak granula pati (Nadia dkk., 2014). Bentuk granula pati varietas Baku Pusus didominasi bentuk ellipsoid dan beberapa polyhedral, sedangkan Baku Tuu Oloyo dan Baku Boan menunjukkan bentuk yang mirip yaitu polyhedral dan triangular menyerupai bentuk granula $D$. alata yang tumbuh di Sri Lanka (Jayakody dkk., 2007). Berdasarkan letak hilumnya, granula pati ubi Banggai termasuk ke dalam tipe amilum eksentris karena hilum berada di tepi granula serupa dengan letak hilum pati kentang (Kumalawati dkk., 2018). Ukuran granula semua varietas beragam Baku Pusus dan Baku Tuu Oloyo didominasi oleh granula berukuran besar, sedangkan Baku Boan memiliki lebih banyak sebaran granula yang berukuran kecil (Tabel 2). Ukuran granula berkisar antara 17,94-23,59 $\mu \mathrm{m}$ (panjang) dan 13,97-16,72 $\mu \mathrm{m}$ (lebar). Granula tanaman Dioscorea yang tumbuh di Venezuela berukuran lebih besar, yaitu 24,5-60 $\mu \mathrm{m}$ (Pérez dkk., 2013).

\section{Komposisi Kimia}

Kadar air ketiga varietas ubi Banggai berkisar antara 10,16-11,70\% (Tabel 3), yang mirip dengan kadar air pati beberapa varietas $D$. alata yang tumbuh di Venezuela (11,8-12,7\%) (Pérez dkk., 2013). Kadar air pati ubi Banggai memenuhi standar mutu Standar Nasional Indonesia (SNI) untuk produk tapioka

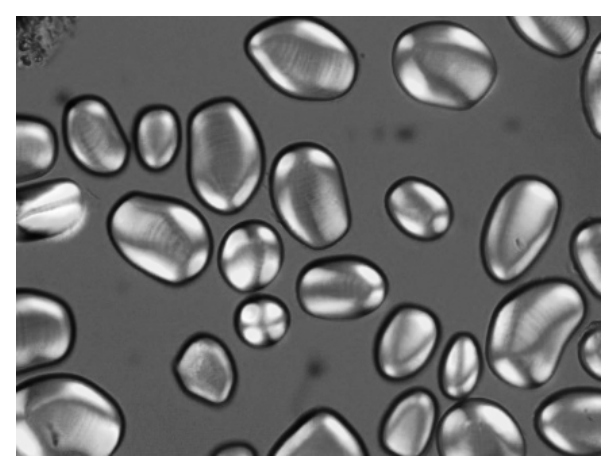

(a)

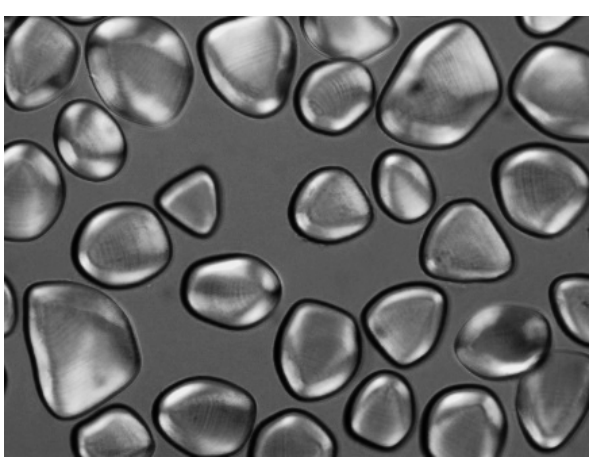

(b)

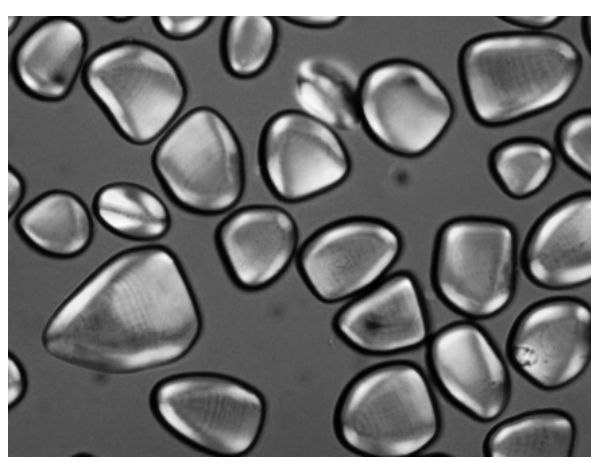

(c)

Gambar 2. Morfologi granula Baku Pusus (a), Baku Tuu Oloyo (b), Baku Boan (c)

Tabel 2. Morfologi granula pati ubi Banggai

\begin{tabular}{llcccc}
\hline \multirow{2}{*}{ Varietas } & \multirow{2}{*}{ Bentuk granula } & \multicolumn{4}{c}{ Ukuran Granula $(\mu \mathrm{m})$} \\
\cline { 3 - 5 } & & Rataan panjang & Rataan lebar & Kisaran panjang & Kisaran lebar \\
\hline Baku Pusus & Ellipsoid, polyhedral & 23,59 & 16,72 & $12,50-35,00$ & $10,00-22,50$ \\
Baku Tuu Oloyo & Polyhedral, triangular & 19,00 & 14,67 & $10,00-27,50$ & $7,50-25,00$ \\
Baku Boan & Triangular, polyhedral & 17,94 & 13,97 & $7,50-27,50$ & $5,00-25,00$ \\
\hline
\end{tabular}


Tabel 3. Komposisi kimia pati ubi Banggai

\begin{tabular}{lccccc}
\hline Varietas & Kadar air (\%) & $\begin{array}{c}\text { Kadar abu } \\
(\% \mathrm{bk})\end{array}$ & $\begin{array}{c}\text { Kadar pati } \\
(\% \mathrm{bk})\end{array}$ & $\begin{array}{c}\text { Kadar amilosa } \\
(\% \mathrm{bk})\end{array}$ & $\begin{array}{c}\text { Kadar amilopektin } \\
(\% \mathrm{bk})\end{array}$ \\
\hline Baku Pusus & $10,80 \pm 0,04^{\mathrm{b}}$ & $0,17 \pm 0,01^{\mathrm{b}}$ & $88,89 \pm 1,41^{\mathrm{a}}$ & $61,91 \pm 0,14^{\mathrm{b}}$ & $26,98 \pm 1,27^{\mathrm{a}}$ \\
Baku Tuu Oloyo & $11,70 \pm 0,08^{\mathrm{a}}$ & $0,21 \pm 0,01^{\mathrm{a}}$ & $88,95 \pm 211^{\mathrm{a}}$ & $60,29 \pm 0,12^{\mathrm{c}}$ & $28,65 \pm 1,98^{\mathrm{a}}$ \\
Baku Boan & $10,16 \pm 0,13^{\mathrm{c}}$ & $0,15 \pm 0,01^{\mathrm{b}}$ & $88,00 \pm 0,18^{\mathrm{a}}$ & $62,88 \pm 0,09^{\mathrm{a}}$ & $25,12 \pm 0,09^{\mathrm{a}}$ \\
\hline Standar* & max. 14 (\%bb) & maks. 0,5 (\%bb) & min. 75 (\%bb) & & \\
\hline
\end{tabular}

Keterangan: Huruf yang berbeda pada baris yang sama menunjukkan perbedaan yang signifikan $(p<0,05)$

*Standar mutu tapioka SNI: 3451.2011 (BSN, 2011)

dan sejenisnya (BSN, 2011). Hasil analisis ragam menunjukkan perbedaan yang nyata $(p<0,05)$ dari kadar air dari pati ubi Banggai. Proses ekstraksi dan perlakuan pengeringan untuk setiap varietas relatif sama, sehingga perbedaan kadar air dapat dipengaruhi oleh kadar air bahan mentah dan tingkat keterikatan air pada setiap varietas yang mungkin berbeda.

Mason (2009) menyatakan bahwa mineral yang terkandung dalam pati dapat mengubah karakteristik viskositas pati, dan pada konsentrasi tertentu dapat menghambat proses retrogradasi pati. Kadar abu pati ubi Banggai berkisar antara 0,15-0,21\%, dan yang paling tinggi adalah Baku Tuu Oloyo (0,21\%) (Tabel 3). Kadar abu pati ubi Banggai ini memenuhi persyaratan SNI, yaitu maksimum $0,5 \%$ bb atau $0,58 \%$ bk (BSN, 2011), yang termasuk kategori rendah $(0,17-0,32 \%)$ (Jayakody dkk., 2007). Karena ketiga varietas ditanam di lokasi yang sama sehingga memiliki kondisi tanah dan perawatan yang sama, maka perbedaan kadar abu dapat disebabkan oleh kandungan mineral alami yang berbeda-beda pada setiap varietas. Kadar abu pati ubi Banggai ini hampir sama dengan delapan varietas D. alata yang dilaporkan oleh Riley dkk. (2006), yaitu 0,19-0,51\%, namun lebih rendah dibandingkan dengan lima varietas $D$. alata di Yogyakarta yang dilaporkan oleh Nadia dkk., (2014) yaitu 0,30-0,91\%. Perbedaan kadar abu hasil penelitian ini dengan yang dilaporkan oleh Nadia dkk. (2014) dapat disebabkan oleh kondisi tanah, lingkungan tempat tumbuh, dan penggunaan jenis pupuk yang berbeda.

Kadar pati dari pati ubi Banggai relatif sama, yaitu berkisar 88,00-88,95\% (bk) (Tabel 3). Kadar pati setiap varietas ini memenuhi syarat mutu SNI untuk produk tapioka dan sejenisnya, karena memiliki total pati di atas $75 \%$ bb atau $87.2 \%$ bk (BSN, 2011). Kadar pati dari tepung ubi Banggai yang dilaporkan Rahardjo dkk. (2016) lebih rendah, yaitu 70,96-84,71\%. Pada umumnya pati tanaman jenis $D$. alata memiliki kadar amilosa yang lebih tinggi jika dibandingkan dengan jenis umbi dan rimpang lainnya. Pati ubi Banggai tergolong unik, karena setiap varietas memiliki kadar amilosa yang tinggi, yaitu di atas $50 \%$ (Tabel 3 ). Varietas Baku Tuu Oloyo memiliki kadar amilosa paling rendah $(60,29 \%)$ dan Baku Boan memiliki kadar amilosa paling tinggi (62,88\%). Kadar amilosa pati ubi Banggai jauh lebih tinggi jika dibandingkan dengan $D$. alata yang tumbuh di Yogyakarta yang memiliki kadar amilosa 24,31-26,99\% (Nadia dkk., 2014) dan yang dilaporkan oleh Oke dkk., (2013) yaitu 27,47\%-41,90\%. Kadar amilopektin yang merupakan selisih dari kadar pati dan amilosa lebih rendah dari sumber pati pada umumnya $(25,12-28,65 \%)$. Pati dengan kadar amilosa yang tinggi dan amilopektin yang rendah ini menyerupai jenis pati amilomaize (Zhong dkk., 2018).

Pati ubi Banggai memiliki karakteristik yang unik dibandingkan pati dari umbi-umbi yang lain, yaitu memiliki kadar amilosa yang tinggi yang menyerupai pati jenis amilomaize. Sumber pati dengan kandungan amilosa tinggi berpotensi diaplikasikan sebagai pembentuk gel (gelling agent). Hal ini ditunjukkan dari pasta ubi Banggai yang memiliki kekuatan gel yang tinggi (Tabel 4).

Kadar amilosa yang tinggi dari ubi Banggai juga berpotensi untuk digunakan sebagai sumber pati resisten tipe II dan bahan baku pembuatan pati resisten tipe III (Akinoso dkk., (2016); Faridah dkk., (2014); Zhao dkk., (2018)). Pati resisten II umumnya terdapat pada sumber pati dengan struktur granula alaminya membuat pati tersebut lama dicerna, seperti pati dari pisang mentah, kentang mentah, dan jagung tinggi amilosa (Zhao dkk., 2018). Penambahan high amylose maize starch (HAMS) pada produk bakery dapat meningkatkan slow digestable starch (SDS) dan resistant starch (RS) serta menurunkan rapidly digestable starch (RDS) (Zhong dkk., 2018). Pati resisten III dibentuk dari perlakuan pendinginan pada pati yang tergelatinisasi. Pasta pati dengan kandungan amilosa tinggi lebih mudah membentuk ikatan hidrogen yang kuat dan membentuk kristal yang kompak yang sulit dihidrolisis setelah proses siklus pendinginanpembekuan (Faridah dkk., 2014), sehingga lebih bersifat resisten. Semakin tinggi kadar amilosa, maka pati memiliki kecenderungan retrogradasi yang tinggi. 
Selama penyimpanan pada suhu rendah molekul amilosa membentuk struktur double helix yang meningkatkan kristalinitas pati menjadi lebih thermostable, sehingga lebih sulit dihidrolisis oleh enzim a-amilase (Khalili dan Amini, 2015).

Potensi aplikasi lain dari pati ubi Banggai adalah sebagai edible coating atau edible film. Kim dkk. (2017) menggunakan pati jagung dengan kadar amilosa lebih tinggi (hingga $80 \%$ ) yang dapat menghasilkan karakter film yang lebih kuat dan lebih tahan air dibandingkan dengan pati jagung dengan kadar amilosa normal (sekitar 28\%).

\section{Kemampuan Mengembang dan Kelarutan}

Varietas Baku Tuu Oloyo memiliki kemampuan mengembang dan kelarutan yang tertinggi, sedangkan varietas Baku Boan memiliki kemampuan mengembang dan kelarutan yang terendah (Tabel 4). Analisis kelarutan dan kemampuan mengembang pati dilakukan secara bersamaan, karena merupakan sifat fisik pati yang saling berkaitan dan keduanya terjadi saat proses gelatinisasi. Persen kemampuan mengembang pati berbanding lurus dengan persen kelarutan. Menurut (Shimelis dkk., 2006), pati dikelompokkan berdasarkan kemampuan mengembangnya, yaitu pati dengan pembengkakan tinggi $(>30 \%)$, sedang/terbatas (16$20 \%)$ dan sangat terbatas $(<16 \%)$. Berdasarkan pengelompokkan tersebut, maka ketiga varietas pati ubi Banggai memiliki kemampuan mengembang yang terbatas. Kemampuan mengembang pati ubi Banggai lebih besar dari pati 10 varietas Dioscorea asal Nigeria yang dilaporkan oleh (Oke., 2013), yaitu 9,49-13,80\%. Kelarutan pati ubi Banggai juga lebih besar dari varietas tersebut $(2,98-6,68 \%)$.

Kadar amilosa dan ukuran granula pati merupakan salah satu faktor yang dapat memengaruhi kemampuan mengembang dan kelarutan. Kadar amilosa yang tinggi dan ukuran granula yang relatif kecil menurunkan kemampuan mengembang dan kelarutan (Riley dkk., 2006). Hal ini sejalan dengan hasil analisis yang menunjukkan varietas Baku Boan memiliki kadar amilosa tertinggi dan ukuran granula relatif kecil, sehingga memiliki kemampuan mengembang dan kelarutan pati terendah. Struktur amilosa yang linier mampu membentuk jaringan internal yang lebih kuat, sehingga kemampuan mengembang dan kelarutan pati menjadi lebih terbatas (Oke dkk., 2013).

\section{Kekuatan Gel}

Pati ubi Banggai cenderung memiliki kekuatan gel yang tinggi, yaitu 396,30 sampai 514,75 gf pada konsentrasi pasta $10 \%$ (Tabel 4). Thao dan Noomhorm (2011) melaporkan pati dari empat varietas ubi jalar memiliki kekuatan gel sebesar 131-266 gf dan pati kacang hijau sebesar 1265 gf. Hasil analisis ragam menunjukkan setiap varietas memiliki kekuatan gel yang berbeda signifikan $(p<0,05)$. Hal ini dipengaruhi oleh kadar amilosa setiap varietas yang berbeda. Pati dengan kadar amilosa yang tinggi cenderung memiliki kekuatan gel yang lebih tinggi, yaitu pada Baku Boan. Struktur amilosa yang linear mampu berasosiasi lebih cepat membentuk jaringan dengan semua fragmen dalam granula sehingga dapat menambah kekuatan gel yang terbentuk (Zhong dkk., 2018). Kekuatan gel yang tinggi dapat menghasilkan produk yang lebih kokoh dan keras akibat retrogradasi pati (Wang dkk., 2016). Namun demikian, pati ubi Banggai mengalami sineresis sebagaimana banyak ditemui pada pati alami.

\section{Derajat Sineresis}

Analisis derajat sineresis dilakukan untuk melihat kemampuan pati ubi Banggai dalam menahan perubahan fisik gel yang tidak diinginkan selama siklus pembekuan (freezing) dan pelelehan (thawing). Molekul air dalam gel pati membentuk kristal es selama pembekuan kemudian saat dicairkan air akan terpisah dengan gel atau mengalami sineresis. Sejumlah air yang terpisah dari gel selama siklus freeze-thaw diukur sebagai nilai stabilitas gel pati terhadap retrogradasi dan derajat sineresis (Wang dkk., 2016). Hasil analisis menunjukkan bahwa nilai derajat sineresis terus meningkat selama tiga siklus freeze-thaw dan setiap varietas memiliki nilai sineresis yang berbeda (Gambar 3). Siklus freezethaw yang berulang menunjukkan kecenderungan retrogradasi sebagai akibat interaksi antara molekul

Tabel 4. Kelarutan, kemampuan mengembang dan kekuatan gel pati ubi Banggai

\begin{tabular}{lccc}
\hline \multicolumn{1}{c}{ Varietas ubi } & Kemampuan mengembang (\%) & Kelarutan (\%) & Kekuatan gel (gf) \\
\hline Baku Pusus & $16,39 \pm 0,16^{\mathrm{b}}$ & $13,41 \pm 0,00^{\mathrm{a}}$ & $442,98 \pm 14,86^{\mathrm{b}}$ \\
Baku Tuu oloyo & $19,77 \pm 0,28^{\mathrm{a}}$ & $14,79 \pm 1,02^{\mathrm{a}}$ & $396,30 \pm 10,66^{\mathrm{c}}$ \\
Baku Boan & $13,47 \pm 0,00^{\mathrm{c}}$ & $8,43 \pm 0,27^{\mathrm{b}}$ & $514,75 \pm 36,25^{\mathrm{a}}$ \\
\hline
\end{tabular}

Keterangan: Huruf yang berbeda pada baris yang sama menunjukkan perbedaan yang signifikan $(p<0,05)$ 
amilosa dengan amilosa, amilosa dengan amilopektin, dan amilopektin dengan amilopektin. Semakin tinggi kadar amilosa maka pati akan lebih mudah mengalami retrogradasi dan membentuk gel yang kuat. Semakin tinggi kecenderungan retrogradasi, maka pati mengalami sineresis lebih tinggi (Wang dkk., 2013). Hal ini sesuai dengan hasil analisis, yaitu varietas Baku Boan cenderung sineresis paling cepat, sedangkan pati Baku Tuu Oloyo cenderung paling lambat.

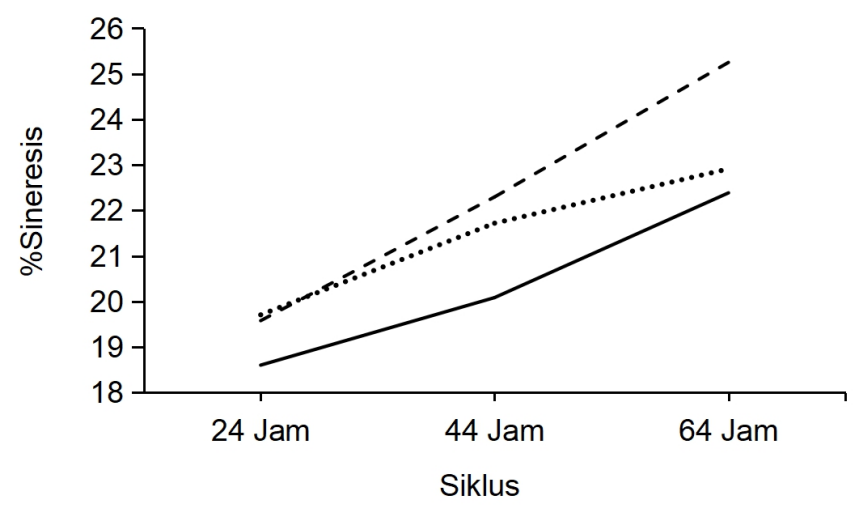

Baku Pusus _ Baku Tuu Oloyo - - - Baku Boan

Gambar 3. Derajat sineresis pasta pati ubi Banggai

Derajat sineresis yang tinggi ini disebabkan oleh tingginya amilosa yang cenderung lebih mudah membentuk ikatan hidrogen selama proses pendinginan. Oleh sebab itu, pati ubi Banggai tidak sesuai untuk digunakan pada produk yang memerlukan penyimpanan pada suhu dingin atau beku, karena dapat memicu pemisahan air dari produk selama penyimpanan. Pati ubi Banggai dapat digunakan untuk produk yang melibatkan proses pembekuan/pendinginan, seperti dalam proses pembuatan soun (Muhandri dkk., 2017). Hal ini juga didukung oleh tingginya suhu awal pasting dan viskositas puncak, yang menunjukkan ketahanan panas yang tinggi, sebagaimana terjadi dalam proses pembuatan soun (Mason, 2009). Pati ubi Banggai juga memiliki kemampuan mengembang yang relatif terbatas, sehingga dapat diharapkan dapat meminimalkan cooking loss soun (Akinoso dkk., 2016).

\section{Profil Pasting}

Profil pasting pati ubi Banggai disajikan pada Gambar 4, dan parameter yang diperoleh dari profil tersebut disajikan Tabel 5. Ketiga varietas memiliki profil pasting yang mirip, yaitu memiliki viskositas maksimum yang tinggi dan mengalami viskositas breakdown. Suhu awal pasting ketiga pati sangat tinggi $\left(80,10-80,35^{\circ} \mathrm{C}\right)$. Hal yang hampir sama dilaporkan oleh Nadia dkk. (2014) untuk $D$. alata, yaitu $81,95-86,38^{\circ} \mathrm{C}$. Proses pemanasan di atas suhu awal pasting menyebabkan peningkatan viskositas, namun kembali menurun setelah mencapai viskositas puncak. Viskositas puncak yang tinggi menunjukkan kapasitas pati ubi Banggai menyerap air dalam jumlah besar sebelum pecah. Viskositas puncak tercapai pada suhu dan nilai viskositas yang berbeda satu sama lain. Pemanasan selanjutnya menyebabkan penurunan viskositas (breakdown viscosity). Nilai viskositas breakdown menunjukkan tingkat kestabilan pasta pati selama proses pemanasan, yaitu semakin tinggi nilai viskositas breakdown, maka pati memiliki kestabilan yang rendah pada proses pemanasan (Jayakody dkk., 2007).

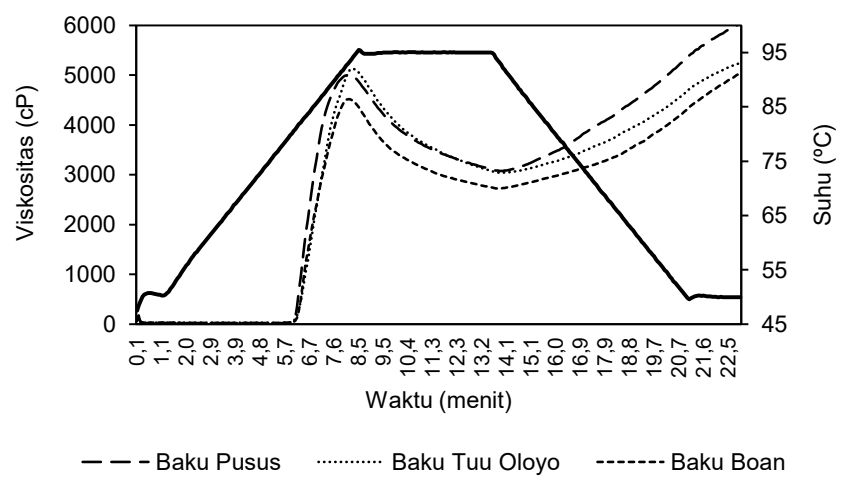

Gambar 4. Profil pasting pati ubi Banggai

Tabel 5. Profil pasting pati ubi Banggai

\begin{tabular}{lccr}
\hline \multicolumn{1}{c}{ Profil Pasting } & \multicolumn{3}{c}{ Varietas } \\
\cline { 2 - 4 } & Baku Pusus & Baku Tuu Oloyo & Baku Boan \\
\hline Suhu awal Pasting $\left({ }^{\circ} \mathrm{C}\right)$ & $80,10 \pm 0,00^{\mathrm{a}}$ & $80,33 \pm 0,32^{\mathrm{a}}$ & $80,35 \pm 0,28^{\mathrm{a}}$ \\
Viskositas puncak (cP) & $5099,00 \pm 138,60^{\mathrm{a}}$ & $5175,00 \pm 65,10^{\mathrm{a}}$ & $4841,50 \pm 454,70^{\mathrm{a}}$ \\
Viskositas breakdown (cP) & $1984,00 \pm 89,10^{\mathrm{a}}$ & $2216,50 \pm 89,10^{\mathrm{a}}$ & $2060,00 \pm 374,80^{\mathrm{a}}$ \\
Viskositas setback (cP) & $2908,00 \pm 45,30^{\mathrm{a}}$ & $2330,00 \pm 190,90^{\text {ab }}$ & $2121,50 \pm 246,80^{\mathrm{b}}$ \\
Viskositas akir (cP) & $6023,00 \pm 4,20^{\mathrm{a}}$ & $5288,50 \pm 74,20^{\mathrm{b}}$ & $4903,00 \pm 166,90^{\mathrm{b}}$ \\
\hline
\end{tabular}


Viskositas pasta pati kembali meningkat ketika suhu diturunkan menjadi $50^{\circ} \mathrm{C}$. Hal ini disebabkan oleh terjadinya reasosiasi molekul pati ketika pasta didinginkan sehingga viskositas pasta pati kembali meningkat yang disebut dengan viskositas setback. Viskositas setback berhubungan dengan kemampuan pati mengalami retrogradasi, yaitu semakin tinggi nilainya menunjukkan pati lebih mudah mengalami retrogradasi. Viskositas setback menunjukkan kecenderungan retrogradasi yang terjadi pada molekul amilosa, dibandingkan amilopektin karena amilosa memiliki struktur yang linear yang lebih mudah mengalami rekristalisasi (Faridah dkk., 2014). Nilai viskositas akhir menunjukkan kemampuan pati membentuk gel setelah proses pendinginan sehingga pada umumnya dijadikan indikator stabilitas pasta ketika diaplikasikan sebagai produk. Ketiga pati ubi Banggai memiliki viskositas akhir yang tinggi, yang menunjukkan kemampuannya membentuk tekstur yang kental dan cenderung membentuk gel yang kuat (Akinoso dkk., 2016).

\section{KESIMPULAN}

Ekstraksi basah ketiga varietas ubi Banggai (Baku Pusus, Tuu Oloyo, dan Boan) menghasilkan pati dengan kadar pati yang tinggi $(88,00-88,95 \%)$ dengan penyusun terbesarnya adalah amilosa $(60,29-62,88 \%)$. Kadar amilosa yang tinggi mempengaruhi sifat lain dari pati ubi Banggai, yaitu kemampuan mengembang yang terbatas, memiliki kelarutan yang tinggi, kekuatan gel dan sineresis yang tinggi. Granula pati ubi Banggai berbentuk ellipsoid, polyhedral, dan triangular dengan ukuran panjang 17,94-23,59 $\mu \mathrm{m}$ dan lebar 13,97$16,72 \mu \mathrm{m}$. Pati ubi Banggai memiliki suhu awal pasting yang tinggi $\left(80,10-80,35^{\circ} \mathrm{C}\right)$. Pada fase pemanasan, pasta ubi Banggai memiliki viskositas puncak yang tinggi dan mengalami viskositas breakdown. Pada fase pendinginan, pasta ubi Banggai memiliki viskositas setback dan viskositas akhir yang tinggi. Perbaikan teknik ekstraksi pati ubi Banggai masih perlu dilakukan agar rendemen yang dihasilkan lebih banyak, termasuk metode untuk menghilangkan lendir yang mengganggu proses ekstraksi. Teknik untuk menghilangkan warna pati ubi Banggai juga dapat dipelajari untuk menghasilkan warna pati yang lebih putih.

\section{KONFLIK KEPENTINGAN}

Penulis menyatakan bahwa tidak ada konflik atau kepentingan dengan pihak lain dalam penulisan naskah publikasi ini.

\section{DAFTAR PUSTAKA}

AACC. (1999). Amylose Content of Milled Rice. In AACC International Methods (pp. 1-4). https://doi.org/10.1094/ aaccintmethod-61-03.01

Akinoso, R., Olatoye, K., \& Ogunyele, O. (2016). Potentials of Trifoliate Yam (Dioscorea dumetorum) in Noodles Production. Journal of Food Processing \& Technology, 7(8). https://doi.org/10.4172/2157-7110.1000609

AOAC. (2012). Official methods of Analysis of The Association Analytical Chemist. AOAC International, 19(2). Gaithersburg (US)

Boy, R., \& Soeharsomo. (2013). Tanaman Umbi-Umbian di Kabupaten Banggai Kepulauan. Prosiding Seminar Nasional Sumber Daya Genetik Pertanian, 151-159.

BSN. (2011). Standar Nasional Indonesia (SNI) Tapioka 3451:2011 Tapioka. Badan Standar Nasional, 1-34.

Faridah, D. N., Fardiaz, D., Andarwulan, N., \& Sunarti, T. C. (2014). Karakteristik Sifat Fisikokimia Pati Garut (Maranta arundinaceae). agriTECH, 34(1), 14-21. https://doi.org/10.22146/agritech.9517

Hirschler, R. (2012). Whiteness, Yellowness, and Browning in Food Colorimetry. In José Luis Caivano (Ed.), Color in Food: Technological and Psychophysical Aspects (pp. 93-104). CRC PRESS.

Jayakody, L., Hoover, R., Liu, Q., \& Donner, E. (2007). Studies on tuber starches. II. Molecular structure, composition and physicochemical properties of yam (Dioscorea sp.) starches grown in Sri Lanka. Carbohydrate Polymers, 69(1), 148-163. https://doi.org/10.1016/j. carbpol.2006.09.024

Khalili, L., \& Amini, A. (2015). Resistant starch in food industry. In Polysaccharides: Bioactivity and Biotechnology. https://doi.org/10.1007/978-3-319-16298-0_42

Kim, H. Y., Jane, J. lin, \& Lamsal, B. (2017). Hydroxypropylation improves film properties of high amylose corn starch. Industrial Crops and Products, 95, 175-183. https://doi. org/10.1016/j.indcrop.2016.10.025

Krishnan, J. G., Padmaja, G., Moorthy, S. N., Suja, G., \& Sajeev, M. S. (2010). Effect of pre-soaking treatments on the nutritional profile and browning index of sweet potato and yam flours. Innovative Food Science and Emerging Technologies, 11(2), 387-393. https://doi.org/10.1016/j. ifset.2010.01.010

Kumalawati, H., Izzati, M., \& Suedy, S. W. A. (2018). Bentuk, Tipe, dan Ukuran Amilum Umbi Gadung, Gembili, Uwi Ungu, Porang dan Rimpang Ganyong. Buletin Anatomi dan Fisiologi, 3(1), 56. https://doi.org/10.14710/ baf.3.1.2018.56-61

Mason, W. R. (2009). Starch Use in Foods. In Starch: Chemistry and Technology, Third Edition (Third Edit). Elsevier Inc. https://doi.org/10.1016/B978-0-12-746275-2.00020-3 
Miller, G. (1959). Use of Dinitrosalicylic Acid Reagent for Determination of Reducing Sugar. In Analytical Chemistry (Vol. 31, pp. 426-428). http://fundacioniai. org/actas

Muhandri, T., Subarna, Koswara, S., Nurtama, B., Ariefianto, D. I., \& Fatmala, D. (2017). Optimasi Pembuatan Sohun Ubi Jalar Menggunakan Ekstruder Pemasak-Pencetak. Jurnal Teknologi dan Industri Pangan, 28(1), 36-45. https://doi.org/10.6066/jtip.2017.28.1.36

Nadia, L., Wiratakususmah, A., Andarwulan, N., Hari, P., Koaze, H., \& Noda, T. (2014). Characterization of Physicochemical and Functional Properties of Starch from Five Yam (Dioscorea alata) Cultivars in Indonesia. International Journal of Chemical Engineering and Applications, 5(6), 489-496. https://doi.org/10.7763/ ijcea.2014.v5.434

Oke, M. O., Awonorin, S. O., \& Workneh, T. S. (2013). Effect of varieties on Physicochemical and Pasting Characteristics of Water Yam Flours and Starches. African Journal of Biotechnology, 12(11), 1250-1256. https://doi. org/10.5897/AJB12.1666

Parwiyanti, F. P., Wijaya, A., \& Malahayati, N. (2015). Swelling dan Kelarutan Pati Ganyong (Canna edulis Kerr.) Termodifikasi Melalui Heat-Moisture Treatment dan Penambahan Gum Xanthan untuk Produk Roti. Prosiding Seminar Hasil Penelitian Tanaman Aneka Kacang dan Umbi, 692-699.

Pérez, E., Rolland-Sabaté, A., Dufour, D., Guzmán, R., Tapia, M., Raymundez, M., Ricci, J., Guilois, S., Pontoire, B., Reynes, M., \& Gibert, O. (2013). Isolated starches from yams (Dioscorea sp) grown at the Venezuelan Amazons: Structure and functional properties. Carbohydrate Polymers, 98(1), 650-658. https://doi.org/10.1016/j. carbpol.2013.06.051

Rahardjo, Y. P., Sumarni, \& Dalapati, A. (2016). Diversifikasi Olahan Ubi Banggai Menunjang Ketahanan Pangan. Prosiding Seminar Inovasi Teknologi Pertanian, 16161624.

Richana, N., \& Sunarti, T. C. (2004). Karakterisasi Sifat Fisikokimiatepung Umbi dan Tepung Pati dari Umbi Ganyong, Suweg, Ubikelapa Dan Gembili. J.Pascapanen, 1(1), 29-37.

Riley, C. K., Wheatley, A. O., \& Asemota, H. N. (2006). Isolation and characterization of starches from eight
Dioscorea alata cultivars grown in Jamaica. African Journal of Biotechnology, 5(17), 1528-1536. https:// doi.org/10.5897/AJB06.388

Shimelis, E. A., Meaza, M., \& Rakshit, S. K. (2006). Physicochemical Properties, Pasting Behavior and Functional Characteristics of Flours and Starches from Improved Bean (Phaseolus vulgaris L.) Varieties Grown in East Africa. E-Journal - Internationale Kommission Für Agrartechnik, January 2017.

Thao, H. M., \& Noomhorm, A. (2011). Physiochemical Properties of Sweet Potato and Mung Bean Starch and Their Blends for Noodle Production. Journal of Food Processing \& Technology, 02(01), 1-9. https://doi. org/10.4172/2157-7110.1000105

Wang, L., Xie, B., Xiong, G., Wu, W., Wang, J., Qiao, Y., \& Liao, L. (2013). The effect of freeze-thaw cycles on microstructure and physicochemical properties of four starch gels. Food Hydrocolloids, 31(1), 61-67. https:// doi.org/10.1016/j.foodhyd.2012.10.004

Wang, W., Zhou, H., Yang, H., \& Cui, M. (2016). Effects of salts on the freeze-thaw stability, gel strength and rheological properties of potato starch. Journal of Food Science and Technology, 53(9), 3624-3631. https://doi. org/10.1007/s13197-016-2350-5

Yeh, A. I., Chan, T. Y., \& Chuang, G. C. C. (2009). Effect of water content and mucilage on physico-chemical characteristics of Yam (Discorea alata Purpurea) starch. Journal of Food Engineering, 95(1), 106-114. https:// doi.org/10.1016/j.jfoodeng.2009.04.014

Yusuf, Sahiri, N., \& Madauna, I. (2015). Pertumbuhan dan Hasil Jenis Ubi Banggai (Dioscorea spp) pada berbagai Pupuk Organik. Agrotekbis, 3(5), 555-563.

Zhao, X., Andersson, M., \& Andersson, R. (2018). Resistant starch and other dietary fiber components in tubers from a high-amylose potato. Food Chemistry, 251, 58-63. https://doi.org/10.1016/j.foodchem.2018.01.028

Zhong, Y., Zhu, H., Liang, W., Li, X., Liu, L., Zhang, X., Yue, H., Xue, J., Liu, X., \& Guo, D. (2018). High-amylose starch as a new ingredient to balance nutrition and texture of food. Journal of Cereal Science, 81, 8-14. https://doi. org/10.1016/j.jcs.2018.02.009 